\title{
Investigation of the Corrosion Behaviour of Aluminium Alloy in Selected Environments
}

\author{
Kalina Kamarska \\ Technical University-Sofia, Branch \\ Plovdiv \\ Department of Mathematics, \\ Physics, Chemistry \\ Plovdiv, Bulgaria \\ e-mail:kamarska@tu-plovdiv.bg
}

\begin{abstract}
The corrosion behaviour of aluminium alloy EN AW-2011 was investigated in selected environments of various electrolytes using gravimetric technique. The results showed that, under the conditions employed in the present work, the corrosion rate of this alloy depends on the specific ions present in solution. The corrosion resistance of aluminium alloy EN AW-2011 is higher in solutions of acids and salts containing sulfate and nitrate ions than in these consisting chloride ions.
\end{abstract}

Keywords-aluminium alloy EN AW-2011, corrosion resistance.

\section{INTRODUCTION}

Aluminium alloy EN AW-2011 is construction material widely used in the automotive industry, aircraft and chemical industries as screw machine products, appliance parts and trim, ordnance, automotive, electronic, fasteners, hardware, machine parts [1]. During its exploitation, in natural or technological environments as electrolytic media, it is in contact with aggressive components and interacting with them is progressively destroyed.

Corrosion of metals is the spontaneous chemical destruction of metals under the effect of their environment [2]. The corrosion study of aluminium and aluminium alloys is of immense technological importance due to their growing industrial application.

The corrosion behaviour of aluminium alloys depends on the chemical resistance of oxide layer of $\mathrm{Al}_{2} \mathrm{O}_{3}$, the characteristics of the parent metal, the chemical composition and the number of the alloying elements [3], [4]. The environments that contain aggressive ions, such as chloride, activate the corrosion process, impair the stability and integrity of the passive layer [5].

In recent years the environmental factors affecting the corrosion behaviour of aluminium and its alloys in salt solutions [6] - [9] and acid solutions [10] - [12], have very often been studied.

The aim of the present investigation is to study the corrosion behaviour of aluminium alloy EN AW-2011 under exposure to selected environments of different acids and salts containing chloride, nitrate and sulfate ions and measure corrosion rate using gravimetric technique.

\section{MATERIALS AND METHODS}

The experiments were performed with samples aluminium alloy EN AW-2011 with an exposed area of $8.54 \mathrm{~cm}^{2}$. For the corrosion tests, a $1 \mathrm{M}$ solutions of various electrolytes such as $\mathrm{HCl}, \mathrm{HNO}_{3}, \mathrm{H}_{2} \mathrm{SO}_{4}, \mathrm{NaCl}$, $\mathrm{NaNO}_{3}$ and $\mathrm{Na}_{2} \mathrm{SO}_{4}$ were used at room temperature $(\approx$ $25^{\circ}$ ).

Before immersion in solution, the experimental samples were washed in detergent for five minutes and then rinsed with distilled water and dried. The dried samples were weighed with an analytical balance Acculab ATILON an accurate to $\pm 0,0001 \mathrm{~g}$ and then were immersed in $100 \mathrm{ml}$ of test solution of $1 \mathrm{M} \mathrm{HCl}$. The system was lightly covered with parafilm. The same process was repeated at different of $1 \mathrm{M}$ solutions of $\mathrm{HNO}_{3}, \mathrm{H}_{2} \mathrm{SO}_{4}$, $\mathrm{NaCl}, \mathrm{NaNO}_{3}$ and $\mathrm{Na}_{2} \mathrm{SO}_{4}$. The first weight loss of each coupon was determined after $4 \mathrm{~h}$ and after that every 192 $\mathrm{h}$ of exposure. The maximum period of exposure was 768 h. After immersion period the samples were cleaned by brushing them under the stream of water using a fibrebristle brush to remove the corrosion products. Then the samples were rinsed with tap water, dried under a stream of air, and weighed. For each of the immersion period the corrosion rate $(\mathrm{Km})$ of alloy were determined using the following equation:

\section{where}

$$
K m=m_{1}-m_{2} / S \cdot 10^{-2} \mathrm{~g} / \mathrm{m} \cdot \mathrm{h}(1),
$$

$m_{1}$ is the weight of the sample, $\mathrm{g} ; m_{2}$ is the weight of the sample after the corrosion test, g; $S$ is the area of the sample, $\mathrm{m}$ and $t$ is the test time, $\mathrm{h}$.

\section{RESULTS AND DISCUSSION}

The gravimetric technique is has proved to be useful in monitoring the corrosion of aluminium alloy in selected environments of different electrolytes. Corrosion of EN AW-2011 was detected in each of the immersion solution as indicated by the weight loss data. The results of obtained are processed by this method and presented in table (Table I and Table II). 
Table I. in solutions of acid $\left(\mathrm{HCl}, \mathrm{HNO}_{3}, \mathrm{H}_{2} \mathrm{SO}_{4}\right)$ and salt $(\mathrm{NaCl}$,

Corrosion rate of aluminium alloy EN AW-2011 in 1M salt solutions

\begin{tabular}{|c|c|c|c|c|c|}
\hline & $4 \mathrm{~h}$ & $192 \mathrm{~h}$ & $384 \mathrm{~h}$ & $576 \mathrm{~h}$ & $768 \mathrm{~h}$ \\
\hline $\begin{array}{c}\text { Solution, } \\
1 \mathrm{M}\end{array}$ & $\begin{array}{l}\mathrm{Km}, \\
g / m . h\end{array}$ & $\begin{array}{l}\mathrm{Km}, \\
g / m . h\end{array}$ & $\begin{array}{l}\mathrm{Km}, \\
g / m \cdot h\end{array}$ & $\begin{array}{l}\mathrm{Km}, \\
g / m \cdot h\end{array}$ & $\begin{array}{l}\mathrm{Km}, \\
g / m . h\end{array}$ \\
\hline $\mathrm{NaCl}$ & 0,14 & 0,020 & 0,023 & 0,020 & 0,014 \\
\hline $\mathrm{NaNO}_{3}$ & 0,09 & 0,004 & 0,020 & 0,014 & 0,013 \\
\hline $\mathrm{Na}_{2} \mathrm{SO}_{4}$ & 0,06 & 0,002 & 0,001 & 0,010 & 0,010 \\
\hline
\end{tabular}

Table II.

Corrosion rate of aluminium alloy EN AW-2011 in 1M acid solutions

\begin{tabular}{|c|c|c|c|c|c|}
\hline & $4 \mathrm{~h}$ & $192 \mathrm{~h}$ & $384 \mathrm{~h}$ & $576 \mathrm{~h}$ & $768 \mathrm{~h}$ \\
\hline $\begin{array}{l}\text { Solution, } \\
1 \mathrm{M}\end{array}$ & $\begin{array}{l}\mathrm{Km}, \\
g / m \cdot h\end{array}$ & $\begin{array}{l}\mathrm{Km}, \\
g / m \cdot h\end{array}$ & $\begin{array}{l}\mathrm{Km}, \\
g / m . h\end{array}$ & $\begin{array}{l}\mathrm{Km}, \\
g / m \cdot h\end{array}$ & $\begin{array}{l}\mathrm{Km}, \\
g / m . h\end{array}$ \\
\hline $\mathrm{HCl}$ & 0,67 & 0,16 & 0,24 & 0,20 & 0,20 \\
\hline $\mathrm{HNO}_{3}$ & 0,30 & 0,26 & 0,40 & 0,36 & 0,37 \\
\hline $\mathrm{H}_{2} \mathrm{SO}_{4}$ & 0,14 & 0,27 & 0,46 & 0,45 & 0,47 \\
\hline
\end{tabular}

The corrosion rate $(\mathrm{Km})$ derived as per equation (1), is plotted against exposure time immersed in aqueous solutions of salts (Fig. 1) and acids (Fig. 2).

\section{EN AW-2011}

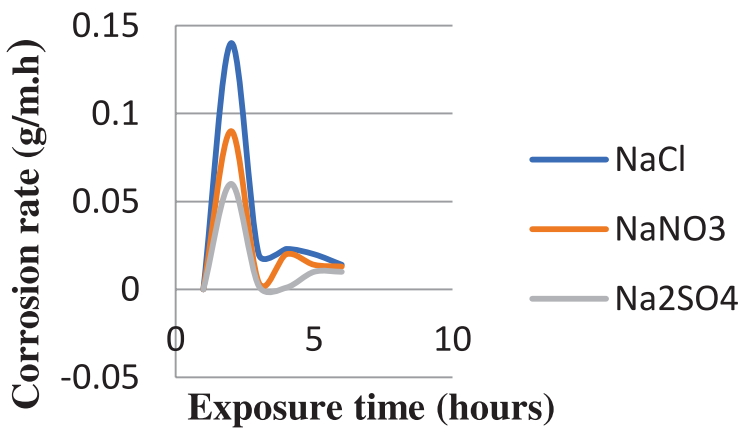

Fig. 1 Corrosion rate of aluminium alloy EN AW-2011 immersed in 1M salt solutions

EN AW-2011

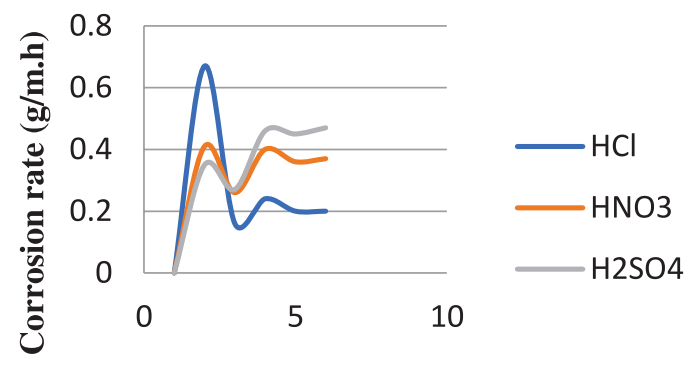

Exposure time (hours)

Fig. 2 Corrosion rate of aluminium alloy

EN AW-2011 immersed in 1M acid solutions

Observation of the graphs shows as initial increase in corrosion rate of aluminium alloy EN AW-2011 with respect to time. During the first four hours of immersion
$\mathrm{NaNO}_{3}$ and $\mathrm{Na}_{2} \mathrm{SO}_{4}$ ) the gaphs achieve the maximum level followed by a sudden decrease in corrosion rate of aluminium alloy. This figure shows that, after 192 hours the corrosion rate increased slightly and stays constant till 768 hours of exposure in test environments.

The behaviour of this process can be attributed to the formation of the protective layer on the alloy surface and increase in corrosion rate with respect to time. Increase in corrosion rate ceases with the formation of the protective oxide layer [13]. When exposed to environment with aggressive ions this oxide layer breaks down at definite sites causing corrosion on the aluminium surface. The corrosion rate of aluminum alloys depends on the specific ions present in solution.

Solutions of most inorganic salts cause insignificant corrosion of aluminum alloys at room temperature [14]. EN AW-2011 showed better corrosion resistances in salt solutions containing sulfate $\left(\mathrm{Na}_{2} \mathrm{SO}_{4}\right)$ and nitrate $\left(\mathrm{NaNO}_{3}\right)$ ions even after $768 \mathrm{~h}$ of immersion. It showed high corrosion rate in $\mathrm{NaCl}$ environment and is found the increasing trend of weight loss.

In acid solution mechanism of dissolution of aluminium and its alloys is as follows [15]:

$\mathrm{Al}+\mathrm{H}_{2} \mathrm{O} \rightarrow \mathrm{AlOH}_{(\text {ads })}+\mathrm{H}^{+}+\mathrm{e}^{-}$

Aluminium alloys most resistant to solutions dilute in sulfuric acid and nitric acid bit hydrochloric acid solutions is definitely corrosive to this alloy. In acid solutions, chlorides greatly stimulate attack of the protective layer [14] and it showed very high corrosion rate.

Alloy EN AW-2011showed better corrosion resistances in $\mathrm{H}_{2} \mathrm{SO}_{4}$ as compared to $\mathrm{HNO}_{3}$ even after 768 $\mathrm{h}$ of immersion.

The results obtained in this work also showed that, in the conditions employed in the present work, the corrosion rate in solutions of acids $\left(\mathrm{HCl}, \mathrm{HNO}_{3}, \mathrm{H}_{2} \mathrm{SO}_{4}\right)$ was higher than of the samples immersed in solutions of salts $\left(\mathrm{NaCl}, \mathrm{NaNO}_{3}, \mathrm{Na}_{2} \mathrm{SO}_{4}\right)$. Furthermore, as shown in the Fig. 2 the corrosion rate of the samples immersed in $0,1 \mathrm{M}$ solutions of $\mathrm{HCl}$ showing the highest corrosion rate. This was followed by the aluminium alloy immersed in $0,1 \mathrm{M}$ solutions of $\mathrm{HNO}_{3}$ and $\mathrm{H}_{2} \mathrm{SO}_{4}$.

Comparison of the corrosion rate of EN AW-2011 from weight loss analysis showed that the solutions of acids and salts consisting sulfate and nitrate ions are found to be less aggressive to the alloy showing relatively less corrosion rates than these consisting the chloride ions. The maximum corrosion rate in presence of chloride ions is indicative of the high penetrating power of these aggressive ions into the barrier oxide layer [16]. Nitrate ions shown the moderate weight loss in presence of these acids and salts. Sulfate ion in the solution appears to impart passivity to the alloy and reduced corrosion rates. The presence of sulfate ion in the medium is probably to produce aluminium sulfates which are less soluble than the other aluminium salts formed in presence of nitrate and chloride ions and may effectively retard the surface degradation [17].

\section{CONCLISIONS}

The present study on corrosion behaviour of 
aluminium alloy EN AW-2011 reveals susceptibility of corrosion in selected environments of various electrolytes of $1 \mathrm{M} \mathrm{HCl}, \mathrm{HNO}_{3}, \mathrm{H}_{2} \mathrm{SO}_{4}, \mathrm{NaCl}, \mathrm{NaNO}_{3}$ and $\mathrm{Na}_{2} \mathrm{SO}_{4}$.

The results obtained in this work showed that, in the conditions employed in the present study, during the first hours of immersion the corrosion rate achieves the maximum level. The corrosion resistance of this alloy depends on the specific ions present in solution and is more in the acid and salt environments containing sulfate and nitrate ions than in the solutions consisting chloride ions.

\section{REFERENCES}

[1] J. R. Davis, Alloying: Understanding the Basics. Ohio: ASM International, 2001.

[2] V. S. Bagotsky, Fundamentals of electrochemistry. Hoboken, NJ: John Wiley, 2006

[3] R. Rachev, Corrosion and protection of metals, Sofia: Novi znania, 2000.

[4] J. Esquivel and R. Gupta, "Corrosion Behaviour and Hardness of Al-M (M: Mo, Si, Ti, Cr) Alloys, "Acta Metall. Sin. (Engl. Lett.), vol.30, pp. 333-341, Feb. 2017.

[5] I. Huang, "Uniform Corrosion and General Dissolution of Aluminium Alloys 2024-T3, 6061-T6, and 7075-T6, "M.S. thesis, The Ohio State University, Columbus, Ohio, USA, 2016.

[6] R. Ambat and E. Dwarakadasa, "Studies on the influence of chloride ion and $\mathrm{pH}$ on the electrochemical behaviour of aluminium alloys 8090 and 2014, "J. Appl. Electrochem., vol.24, pp. 911-916, Sept.1994.

[7] V. Guillaumin and G.Mankowski, "Localized corrosion of 2024 T351 aluminium alloy in chloride media, "Corros Sci., vol. 41, pp. 421-438, July, 2000.
[8] A.Mazhar, S. Arab, E. Noor, "The role of chloride ions and pH in the corrosion and pitting of Al-Si alloys, "J. Appl. Electrochem., vol. 31, pp. 1131-1140, May, 2001.

[9] J. Datta, C. Bhattacharya, S. Bandyopadhyay, "Influence of $\mathrm{Cl}^{-}$, $\mathrm{Br}^{-}, \mathrm{NO}_{3}{ }^{-}$and $\mathrm{SO}_{4}{ }^{2-}$ ions on the corrosion behaviour of 6061 Al alloy, "Bul. Mater. Sci., vol. 28, pp 253-258, June, 2005.

[10]N. Obi-Egbedi, I. Obot, S. Umoren, " Spondias mombin L. as a green corrosion inhibitor for aluminium in sulphuric acid: Correlation between inhibitive effect and electronic properties of extracts major constituents using density functional theory, “ Arab. J. Chem., vol. 5, pp. 361-373, Sept. 2012.

[11] L. Nnanna, I. Anozie, A. Avoaja, C. Akoma, E. Eti, "Comparative study of corrosion inhibition of aluminium alloy of type AA3003 in acidic and alkaline media by Euphorbia hirta extract, “ Afr. J. Pure Appl. Chem. vol.5, 265-271, Aug. 2011.

[12]D. Prabhu and R. Padmalatha, "Studies of corrosion of aluminium and 6063 aluminium alloy in phosphoric acid medium, "International Journal of Chem. Tech Research, vol. 5, 2690-270, Jan. 2013

[13] R, Tolulope Loto and A, Adeleke, "Corrosion of Aluminum Alloy Metal Matrix Composites in Neutral Chloride Solutions, "J Fail. Anal. and Preven., vol. 16, pp. 874-885, July, 2016.

[14]E. Ghali, "Aluminum and Aluminum Alloys," in Uhlig's Corrosion Handbook, Second Edition, R.W. Revie, Ed. Wiley, Hoboken, 2000, pp. 677-715.

[15]I. Obot, N. Obi-Egbedi, S. Umoren, E. Ebenso, "Synergistic and antagonistic effects of anions and Ipomoea invulcrata as green corrosion inhibitor for aluminium dissolution in acidic medium, "Int. J. Electrochem. Sci., vol. 5, pp. 994-1007, July, 2010.

[16]L. Tomcsanyi, K. Varga, I. Bartik, G. Horanyi, E. Maleczki, "Electrochemical study of the pitting corrosion of aluminium and its alloys-II. Study of the interaction of chloride ions with a passive film on aluminium and initiation of pitting corrosion, “ Electrochim. Acta, vol. 34, pp. 855-859, June, 1989.

[17] S. Pyun, S. Moon, S. Ahn, S. Kim, "Effects of $\mathrm{Cl}^{-}$ , $\mathrm{NO}_{3}$ - and $\mathrm{SO}^{2-}$ ions on anodic dissolution of pure aluminum in alkaline solution, " Corros. Sci., vol. 41, pp. 653-667, Apr. 1999. 